\title{
Stress Testing of Retail and Corporate Segments of Russian Credit Market
}

\author{
Alexander M. Karminsky ${ }^{1}$, Oleg S. Kozlov ${ }^{2}$ \\ Academic Department of Finance, National Research University Higher School of Economics, Russia \\ EY, Assurance, Fraud Investigation and Dispute Services, Russia \\ ${ }^{1}$ Email: karminsky@mail.ru \\ ${ }^{2}$ Email: oleg.s.kozlov@ru.ey.com
}

\begin{abstract}
The objective of the paper is to investigate and compare risk patterns in retail and corporate segments and assess the potential impact of macroeconomic shocks on loan quality. Banks' monthly financial statements data for the period 2004 - 2012 are used. Firstly, we develop an indicator to measure institution's credit risk that reflects variance and average value of NPL corrected for loan loss reserves. It is used to compare the risk-return patterns of largest stateowned banks, and under our framework we identify how the strategies of various banks differ in retail and corporate loans, identifying 'safest' and 'riskiest' institutions. Secondly, loan growth and credit risk sensitivity to macroeconomic shocks is analyzed using vector auto-regression. Macroeconomic shocks do not significantly increase NPL growth in the corporate segment. However, inflation and investment growth have a considerable impact on NPL growth in the retail segment (which is however almost three times less than the corporate). Based on these findings we conclude that there is no reason to expect rampant rise in corporate loan defaults in response to sudden changes in macroeconomic environment of Russia, though further growth of corporate loan segment increases credit risk, while the opposite is true about the retail sector.
\end{abstract}

Keywords: Stress testing, Credit market, Russia, Non-performing loans, State banks

\section{Introduction}

Global financial turmoil emphasizes the importance of efficient monitoring of banking system stability and stress testing is one of the most widely used tools in this area, which enables us to estimate the impact of macroeconomic shocks on financial sector. The recent economic crisis has clearly shown that financial stability can be significantly affected by macroeconomic environment in addition to bank-specific factors; hence, the importance of efficient estimates of banking system vulnerability to real shocks is increasingly important.

Despite its acknowledged importance we are still on the way to a uniform methodology of system-wide stress-tests, though IMF has published a number of relevant recommendation documents (IMF, 2012, IMF, 2011b, Ong et al., 2010), which contains best practice principles', peculiarities of stress-testing in case of limited data availability for developing countries and other useful guidelines which should complement further practices in this field. In case of Russia IMF (2011a) pointed that the methodology of Russian Central Bank (RCB) in conducting stress-tests can be improved in order to implement more involved estimation techniques and to comply with Basel II recommendations on assessing credit risk. Recent foreign studies, which perform stress tests of Russian banking sector (e.g. Fungáčová and Jakubík, 2012) usually, implement up-to-date estimation methods but use generally accepted in European studies estimates of credit risk parameters in calculating expected loss given default may lead to erroneous results when applied to Russia. This study aims to fill the gap and provide a comprehensive set of up-to-date though easy-to-use techniques that can be used for assessing potential risks allowing the distinction between corporate and retail segments of Russian credit market.

Section 2 provides an overview of theory and practice of stress-testing including most recent recommendations and best practice principles with special attention to Russian experience. Section 3 contains discussion of general trends of growth and credit risk in corporate and retail segments of Russian credit market. Section 4 provides deals credit risk in several major state-controlled banks under the developed Credit Risk - Return Stability framework. Section 5 presents the results of stress tests derived from a comprehensive VAR model, which estimates the relations between real and financial sectors. Section 6 concludes. 


\section{Notes on Theory and Practice of Stress Testing}

\subsection{Brief introduction into fundamentals of stress testing}

Nowadays there is growing amount of literature on stress testing and this term may refer to very different practices. Here we are concerned with what IMF (2012) calls Macro prudential/surveillance stress testing, which is performed on a system-wide level by country authorities and practitioners. System-wide stress tests can be broadly defined as a range of techniques used to assess the vulnerability of a financial system to 'exceptional but plausible' macroeconomic shocks (Blaschke et al., 2001).

An important distinction made between top-down and bottom-up tests. The bottom-up approach implies first performing individual stress tests for each of the financial institution and then aggregating results to perform a general test of the system as a whole. Top-down approach requires first aggregating data across individual banks and then performing a test based on the data. We follow the latter approach due to data availability considerations.

It is difficult to establish a universal methodology, though Sorge (2004) reports typical stages of stress testing. Firstly, we need to identify the scope of analysis and potential risks and vulnerabilities of the system. Secondly, it is required to define shocks and design relevant scenarios, all assumptions should be listed. Thirdly, a researcher maps macro shocks to banks' balance sheets using an econometric model. Finally, we interpret results; second-round effects are analysed, and the limitations of the performed analysis should be carefully discussed. We now discuss each stage in more detail.

Another step towards uniformity was undertaken by IMF (2012) outlining general principles and guidelines for stress testing. It is noted that relevant institutions are selected, concerning size, substitutability and interconnectedness. Another important issue is feedback effects between financial and real economy sectors, which are often left out of consideration. All material risks and buffers should be included and the viewpoint of different experts should be considered: supervisory authorities, commercial banks experts and academia representatives.

These principles are the core for stress testing and should be kept in mind by any researcher working in this field. However, instructions that are more specific are needed concerning specific type of test for a specific country; hence, we proceed to the discussion of particular tests in Russia.

\subsection{Critical review of Central Bank of Russia stresses testing practice}

Russia is an example of a country with rather young financial system which experienced a difficult transition period in the 1990s and is yet on its way to sustainable development. A key feature of Russian banking sector is a dominance of state-controlled banks which accounted for 50-55\% of credit market for the past 10 years. Central Bank of Russia (CBR) is the supervisory authority and the lender of last resort, which aims at financial stability and development, and stress testing is a crucial tool for CBR in its policy. Since 2003, the CBR has conducted aggregate top-down stress tests twice a year according to IMF and World Bank methodologies, as Basel Commission on Banking Supervision requires supervisory authorities to perform stress-testing exercises regularly (BCBS, 2009).

As for its methodology, according to the report on financial stability in 2011 (CBR, 2012), a macroeconomic model is used which is essentially a system of linear regressions which describes the relation between macro and financial system variables. For each credit institution it is calculated what impact the macro shock would have on balance sheet parameters. The results of stress testing are the estimated losses and expected need for recapitalization. Current time horizon is one year and all credit institutions are included in the sample.

Among strengths of CBR approach IMF (2011a, p. 15) acknowledges that, firstly, it provides overwhelming coverage of the banking sector (the test covers all the banks in the system). Secondly, comprehensive coverage of the types of risks (in addition to credit risk, which is usually the sole focus of macro stress testing models, the CBR's model covers market (equity, exchange rate, and interest rate) risks and liquidity risks). Thirdly, it includes different macro-financial linkages, including various channels of feedback (second round) effects. Finally, the estimated core macro-financial linkages seem to be in line with actual experience and IMF estimates.

Several areas for improvements and recommendations are outlined as well (IMF, 2011a, p. 14). Firstly, the number of banks included can be reduced for the goal of increased efficiency and more robust econometric performance. It is noticed that 250 banks, constituting 95 per cent of sector's assets, is a preferred representative sample size which enables to use more advanced econometric tools. Secondly, the time horizon could be extended to 2-3 years and beyond, as the model would enable to capture possibly long-lasting lagged effect of a severe shock (this suggestion should be treated with caution because emerging financial systems are more volatile and estimated coefficients of longrun effects are not likely to be robust). Thirdly, the current approach of CBR to construct a large system of equations estimated by OLS is subject to technical issues such as omitted variables and auto-correlated errors. IMF proposes to 
use smaller main macro model and a range of separate, satellite models (commonly applied estimation tools are VECM and VAR). Thirdly, credit risk modelling could be expanded to incorporate Basel II-type portfolio loss concepts (e.g. credit $\mathrm{VaR}$ ) instead of using increases in NPL as a measure of credit quality (and assumed full provisioning for new NPLs).

\subsection{Alternative approaches to stress testing Russian financial system}

There are several academic papers and independent agencies' reports that implement more elaborative methodologies to stress test Russian financial system on an aggregate level. An outstanding example of implementing up-to-date stress testing approach is a recent discussion paper of Bank of Finland Institute for Economies in Transition Bank stress tests as an information device for emerging markets: The case of Russia by Fungáčová and Jakubík (2012). Their methodology consists of five steps. Firstly, they create a baseline and adverse macroeconomic scenarios. Secondly, stress parameters are forecasted through 'satellite' models. Thirdly, the projected via satellite models values are used to calculate credit, foreign exchange and interest rate risks for each bank. Fourthly, iterative interbank contagion is taken into consideration as follows. After losses are deducted from bank capital and post-shock capital adequacy ratios (CAR) are computed, the latter are mapped into bank-specific PD (using expert judgment) and they are used to determine the likelihood of institution's default on interbank liabilities. Finally, post-shock and post-contagion CARs are calculated and recapitalization costs are estimated on a bank-specific level.

The results of tests suggest that Russian banking sector is rather sensitive to changes in the macroeconomic environment, high credit risk and cyclicality combined with the low level of financial intermediation dampen economic development under baseline scenario (Fungáčová and Jakubík, 2012, p. 17). In the baseline scenario CAR for 33.5\% of banks included in the sample fall below the regulatory minimum of $10 \%$ and the total recapitalization costs would reach $0.6 \%$ GDP in 2011. Under the adverse scenario $40 \%$ of banks would need recapitalization equal to $0.8 \%$ of GDP - the results are comparable with the ones obtained by CBR though more precise.

This paper provides a thorough analysis including careful separate treatment of risks and taking into account contagion effects. However, authors sacrifice overall model consistency for more robust results. Several technical assumptions are rather strong, e.g. the assumption that same growth rates of dependent variables in satellite models are applied to all banks and the assumptions that all banks behave as if they were complying with the Basel II framework, even if it is not fully implemented in Russia. Some necessary parameters such as LGD and EAD are set based on anecdotal evidence, as authors admit (Fungáčová and Jakubík, 2012, p. 13). Nevertheless, this paper is a good example of how modern stress test practices could be applied to Russia and should be considered as an important point for reference.

However, there is an array of papers of Russian researchers conducting independent stress tests of domestic financial stability and the most notable institution in this field is Center for Macroeconomic Analysis and Short-term Forecasting (CMASF), which has recently produced a number of works in this field which combine deep knowledge of Russian banking sector practices with sophisticated estimation techniques used in stress testing and hence obtain reasonable outcomes worth discussing (Pestova 2012, Solntsev et al., 2012). Based on internal macroeconomic model computed in CMASF expected the need for capitalization is estimated under different scenarios using estimates obtained from crosscountry data. In addition to macroeconomic scenarios Sontsev et al. (2012) analyses prudential scenarios which is very demanded in the light of current Basel II and Basel III implementation. However, the limitations of methodology are implementing average cross-country estimates for the case of Russia, which is a potential source of inaccuracy in forecasts and lack of transparency, as internal macroeconomic forecasting models are not disclosed. There is also no distinction between retail and corporate segments, which are important as, will be shown further.

Based on the papers dedicated to theory and practice of stress tests we now elaborate our own methodology. Taking into account IMF (2012) recommendations we begin by identifying general trends in the banking sector of Russia and then focus on systematically important institutions - state banks under our novel framework. Concerning the stress test itself the crucial distinctive feature of this paper is statistical approach used to attain higher objectivity as we do not use scenarios as shock events but consider a one standard deviation shock in the appropriate variable. This makes it difficult to compare results of this study with the papers discussed although it provides some novel insights discussed below.

\section{Overview of General Trends in Corporate and Retail Segments of Russian Credit Market}

Before we begin the analysis of risks, vulnerability in each sector we briefly look at market size dynamics in corporate and retail segments of Russian credit market (we do not consider interbank sector due to its smaller size and the fact that most of the loans are short-termed, and hence the ratio of non-performing loans is closed to zero). 


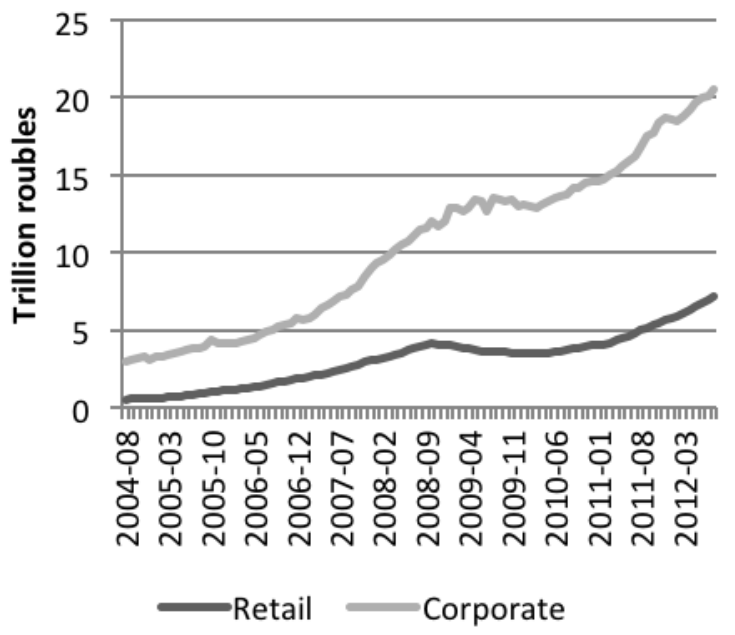

Source: Author's calculations based on Mobile

Figure 1: Size of credit market segments

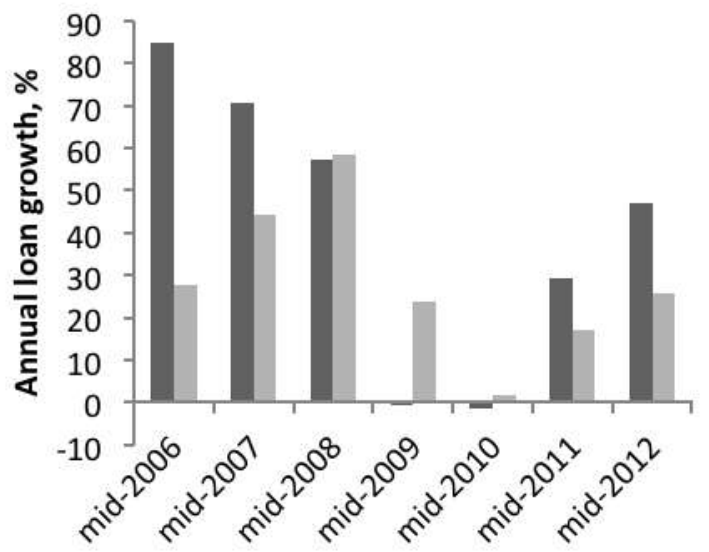

Retail loan growth $\quad$ Corporate loan growth

Figure 2: Annual growth rates

Figure 1 reflects total volume of the loan provided in each sector, and the first thing to notice is that volume of corporate loans given exceeds that of the retail sector (on average by 4.3 times). For the eight years period 2004-2012 corporate loans segment has grown by 7 times from around 3 to 21 trillion roubles, however, retail sector has grown by 14 times from around 0.5 to 7 trillion roubles, i.e. the overall growth rate of retail sector is twice as much as that in the corporate sector for the entire period. Figure 2 provides annual growth rates dynamics, and there are several points to mention. Before the 2008-2009 crisis the growth rates of retail loan sector were very high though decreasing from enormous $85 \%$ by mid- 2006 to $60 \%$ by mid-2008, while growth rates in corporate loan sector steadily grew from $28 \%$ by mid-2006 to almost catch up almost exactly the rate of growth in retail segment. The crisis hit retail sector harder as it has shown negative growth rates for two years while from July 2008 to July 2009 corporate loan sector has grown by $24 \%$ per cent despite the recession. Nevertheless, the retail sector is growing much faster than the corporate by $39 \%$ and $47 \%$ respectively for the last two years compared to $17 \%$ and $26 \%$ growth in corporate loans. Hence, although we bear in mind that retail loan sector is recovering from two years of negative growth rates, Figure 1 shows that by mid2011 the pre-crisis level of 4 trillion roubles had been surpassed and the recent sharp growth of almost 50\% may be the signal of a growing bubble, acknowledged not only by market participants but also in academia (Solntsev et al., 2012).

Russian banks are not obliged to provide statements in accordance with IFRS and hence instead of the accepted in the literature measure of non-performing loans (classified as a loan the payment for which is overdue more than 90 days) we implement the measure of overdue loans reported in accordance with Russian accounting standards, however, for conventional reasons we refer to it as the ratio of non-performing loans in loan portfolio.

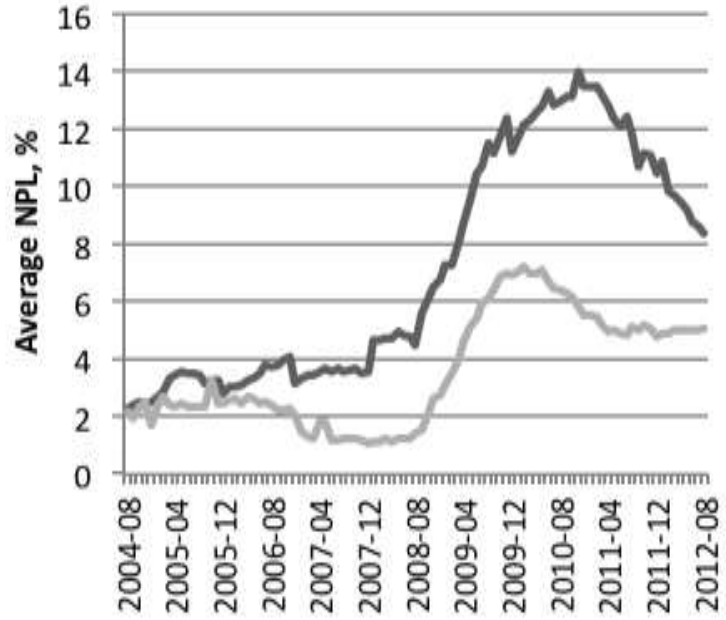

Retail loan segment

Corporate loan segment

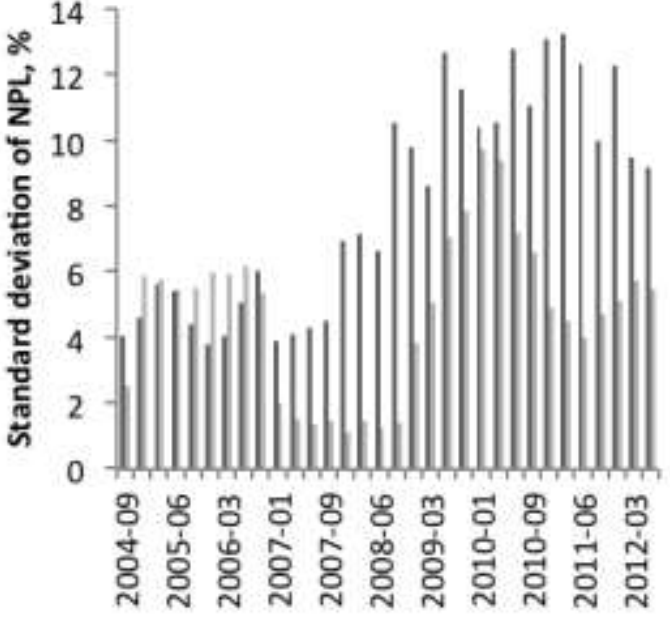

Eetail loan segment

E Corporate loan segment
Source: Author's calculations based on Mobile Figure 3: Average NPL
Figure 4: Standard deviation of NPL 
Figure 3 shows that the ratio of non-performing loans has been significantly higher in the retail sector since the divergence initiated back in 2005. NPL in the retail sector peaked as high as $14 \%$ by the year 2011 since the surge, which began in 2008 when it was around $4 \%$. Nevertheless, since the end of 2010 it has been steadily falling to $8 \%$ by August 2012. In corporate credit sector NPL increased because of crisis and has not returned to pre-crisis level as well, it peaked at $7 \%$ as of the end of 2009 and fluctuated around 5\% since then. Hence, the current picture is encouraging: if the trend stays in power, NPL in both sectors would eventually converge.

Standard deviation in NPL (see Figure 4) in retail sector has been significantly higher, especially for 2 years before the crisis (retail standard deviation of NPL being as much as 7 times higher) and during 2010-2011. Dynamics in standard deviation of corporate NPL is more pro-cyclical: it has been rather large (on average 5\%) during 2004-2006 turmoil, as low as $1 \%$ during the upturn of 2007-2008, steadily grew to peak at $9 \%$ by the end of 2009 , decreased since then to local minimum of $4 \%$ in mid-2011 and has been steadily increasing since then which is an alarming sign. Standard deviation in retail NPL is more chaotic and has stayed at crisis levels of 10-12\% for the last 3 years, indicating that this segment of the credit market is yet on its way to stabilize.

The main points to mention is that corporate loan segment is three bigger than the retail and while both have been growing rapidly for past 10 years the level of NPL in retail sector as well as its standard deviation has been approximately 2 times higher than in corporate sector. This preliminary analysis, therefore, makes us conclude that significantly more credit risk is concentrated in retail loan segment. We now proceed to institution-specific analyses of systematically important state banks.

\section{Bank-Specific Analysis of Credit Risk in Retail and Corporate Loan Segments}

\subsection{Credit Risk - Return Stability framework: outlines}

Our framework is based on the back-testing procedure described in Čihák (2007), p. 26. The idea is to set the value of NPL on vertical axis and CAR on the horizontal and plot banks on the plane in these coordinates on a specified date. Median values of NPL and CAR can be set as thresholds and banks with high NPL and low CAR are classified as 'risky' while those with low NPL and high CAR - as 'safe'.

In order to complement our analysis, we implement Z-score (first derived in Roy, 1952) instead of CAR as it additionally reflects information on return stability. We define it to measures the probability that bank losses fall below the regulatory capital minimum (taken as N1 normative stated by CBR to be 10\%), i.e. that bank will be insolvent. Assuming returns follow a distribution with finite first moments $\mu$ and ${\sigma_{r}}^{2}$ according to Chebyshev's theorem we can estimate the upper bound of probability of insolvency:

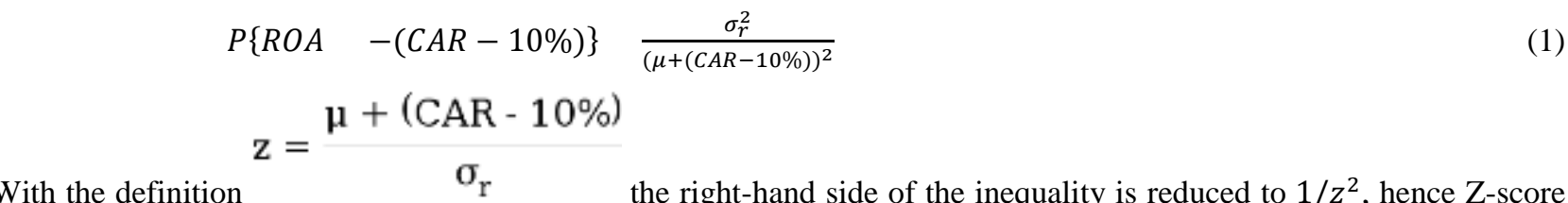
is a distance-to-insolvency measure. Following conventional practices (Ivičić et al., 2008) and our general trends analysis in previous section we decide to take 3 years window to provide an estimate of $\mu$ to be average ROA for the last three years and the estimate of $\sigma_{r}$ to be standard deviation of ROA for the last three years.

As for the credit risk we propose a novel measure which takes into account average and standard deviation of NPL and loan loss reserves. The logic is the same as behind $\mathrm{Z}$-score and below we provide explicit derivation.

Chebyshev's theorem (inequality) is stated for some random variable $x$ and some arbitrarily chosen constant $\mu$ as follows:

$$
P\{|x-E(x)|>\mu\} \quad \frac{\operatorname{Var}(x)}{\mu^{2}}
$$

Define $x=N P L, \mu=L L R-E(N P L)$ and apply the definition of absolute value:

$$
\begin{gathered}
P\{|N P L-E(N P L)|>L L R-E(N P L)\}= \\
\mathrm{P}(\mathrm{NPL}>\mathrm{LLR})+\mathrm{P}(\mathrm{NPL}<2 \mathrm{E}(\mathrm{NPL})-\mathrm{LLR}) \geq \mathrm{P}(\mathrm{NPL}>\mathrm{LLR})
\end{gathered}
$$

Hence, we get an upper bound probability estimate that NPL would exceed loan loss reserves:

$$
P(N P L>L L R) \quad \frac{\operatorname{Var}(N P L)}{(L L R-E(N P L))^{2}}
$$


We define the new measure of credit risk, Z (NPL) statistic, similarly to the conventional Z-score (which we further refer to as $\mathrm{Z}(\mathrm{ROA}))$ :

$$
Z(N P L) \equiv \frac{L L R-E(N P L)}{\sqrt{\operatorname{Var}(N P L)}}
$$

Note that higher reserves a bank holds, lower expected NPL, computed as average for 3 years and lower the standard deviation of NPL result in higher values of the statistic and thus indicate bank's stability against credit risks. Z (NPL) is superior compared to a simple NPL as it takes into account historic average value of NPL and its volatility as well as the information on current credit risk buffer in the form of loan loss reserves. The statistic could be easily computed for emerging countries as well as it only requires information on NPL and LLR and could be used to quickly assess credit risk exposure of different segments of credit market without much computational burden. It is theoretically appealing as well as it rests only on the assumption that NPL follows at least some distribution as Chebyshev theorem is applicable to any distribution with finite first two moments compared to the conventional Value-at-Risk methodology the assumptions of which rest on a number of empirically estimated parameters. One should bear in mind however how NPL is calculated and whether the data on it is reliable, hence some filters could improve the indicator.

For Russian banks we compute it separately for corporate and retail loan sectors; for the former taking as the measure of LLR the balance of 44915, 45015, 45215, 45315 and 45615 accounts (loan loss reserves for corporate borrowers: state-controlled commercial entities, state-controlled non-commercial entities, private commercial entities, private noncommercial entities and foreign entities respectively) and for the latter the sum of the balances of 45415 and 45515 (loan loss reserves for individual entrepreneurs and individuals credit respectively). This data is taken from the 101 form (balance sheet), however there is missing data so here we demonstrate the statistic on a reduced sample of state banks as of the latest period available, $1^{\text {st }}$ September 2012. Thresholds are chosen to be median values of Z (NPL) and $\mathrm{Z}$ (ROA) for the sample.

\subsection{Retail loan segment analysis under Credit Risk - Return Stability}

For the retail sector as we can see from Figure 5 Gazprombank is the leader with the highest Z(NPL) score of nearly 9 because of rather high LLR of 2\% compared to rather low NPL which has not varied much throughout 2004-2012 (standard deviation of NPL $=0.3 \%$ ). However, it does not enter the 'safe' banks quadrant because of slightly lower $Z$ (ROA) than the benchmark, again mostly because of low CAR. The other three banks have negative Z (NPL) meaning that their current level of loan loss provisions is less than their average ratio of NPL. Surprisingly, Sberbank appears in the 'risky' sector although it was in 'safe' quadrant on the Figure 14 where the analysis was limited to point-in-time NPL and CAR estimates only. This outcome is largely motivated by Sberbank holding reserves for retail loans as low as $1.78 \%$ of its large retail credit portfolio, compared to $3.5 \%$ average NPL for the last three years. VTB24 has Z (NPL) $=$ -2.5 and VTB has $\mathrm{Z}(\mathrm{NPL})=-4.3$.

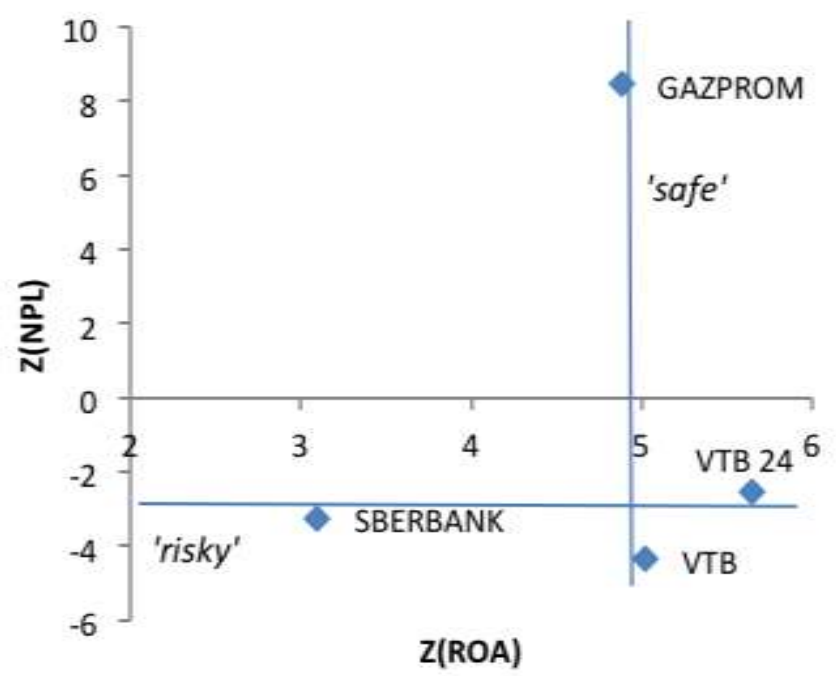

Figure 5: Credit risk - return stability framework, retail loans, 01.09.2012

\subsection{Corporate loan segment analysis under Credit Risk - Return Stability}

On Figure 6 VTB is in the 'risky' quadrant though with Z (ROA) close to the median. Gazprombank has the highest Z (NPL) of 3 and it is the only bank with positive Z (NPL) similar to the retail sector. Sberbank is again close to 'risky' sector, on the border - if its Z (NPL) decreases further, it will migrate to the risky banks classification according to this 
framework. The only bank that appears to be 'safe' in corporate loan sector is the Vneshekonombank's affiliate Globex bank which has relatively high Z (ROA) and approximately balanced by reserves average NPL for the last three years.

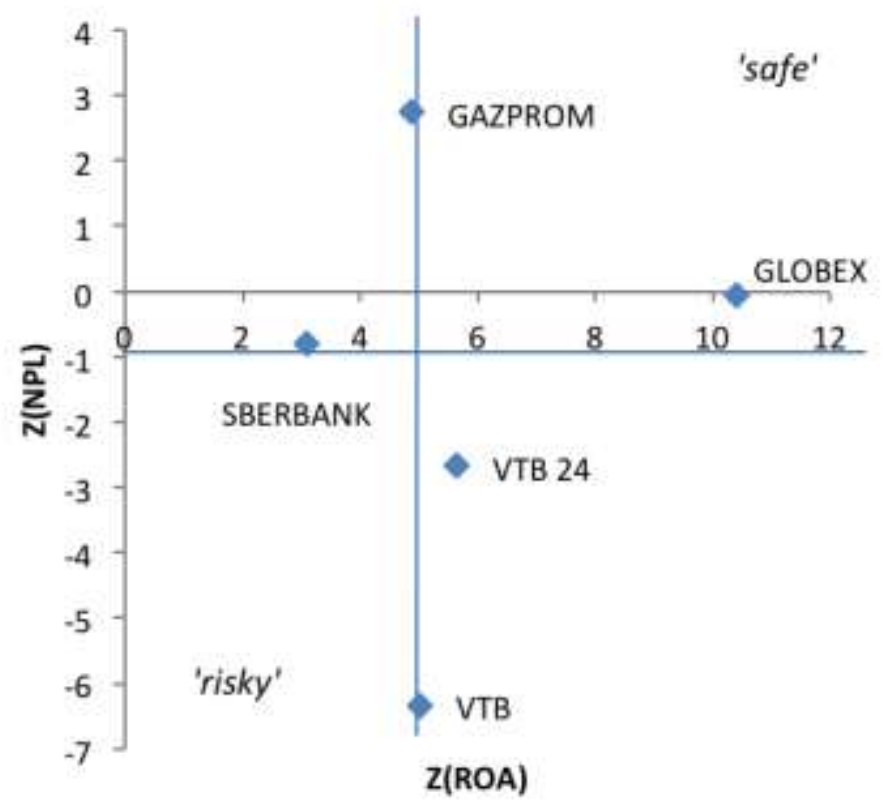

Figure 6: Credit risk - return stability framework, corporate loans, 01.09.2012

Comparing Figures 5 and 6 we note that average Z(NPL) in the corporate loan sector $(-1.5)$ is higher than in the retail ($0.4)$ which suggests that contrary to the general trends analysis presented in the previous section corporate loan sector is more risky. Hence, as of 01.09.2012 more credit risk is concentrated in corporate loan segment for systematically important institutions, and supervisory authorities thus should monitor carefully state banks on the corporate loan segment of the credit market. The analysis can be extended to include more banks, look at several points in time and tracing position of a single bank during some specified period - this simple framework provides various possibilities for both supervisory bodies and risk management of individual bank.

\section{Data and Methodology}

\subsection{Data and sampling}

We now return to the system-wide level to investigate the relationship between NPL in different sectors and key macroeconomic variables and system-wide variables.

For data on bank-specific indicators Mobile's "Banks and Finance" database was used, which is compiled directly from Russian banks' financial statements and covers the period September 2004 - September 2012 (monthly).

The sample was drawn as follows. For each segment, we list all credit organizations (1486 in total) as of September 1, 2004 by the amount of loans they provided in descending order. The first $\mathrm{N}$ banks, which cumulatively account for $85 \%^{1}$ of the market are included in the sample. We allow the same bank to be in both segment samples, in a sense treating its corporate loan and retail loan departments, as separate banks as further their operation will be explained by different factors for each segment. Hence, as of the $1^{\text {st }}$ of September 2004 we had 104 banks in the sample for the corporate segment and 97 banks in retail loans segment. Despite in the following periods some of the chosen banks left the market and the share of the others changed, on average the share of sampled banks in corporate credit fluctuated between 85 and 89 per cent of the market, and in retail segment of the sampled banks covered 82-90\% (see Figure 7), hence we conclude that the sample stays highly representative throughout the period under consideration.

\footnotetext{
${ }^{1} 85$ per cent coverage was chosen as the median value from similar studies (IMF, 2012)
} 


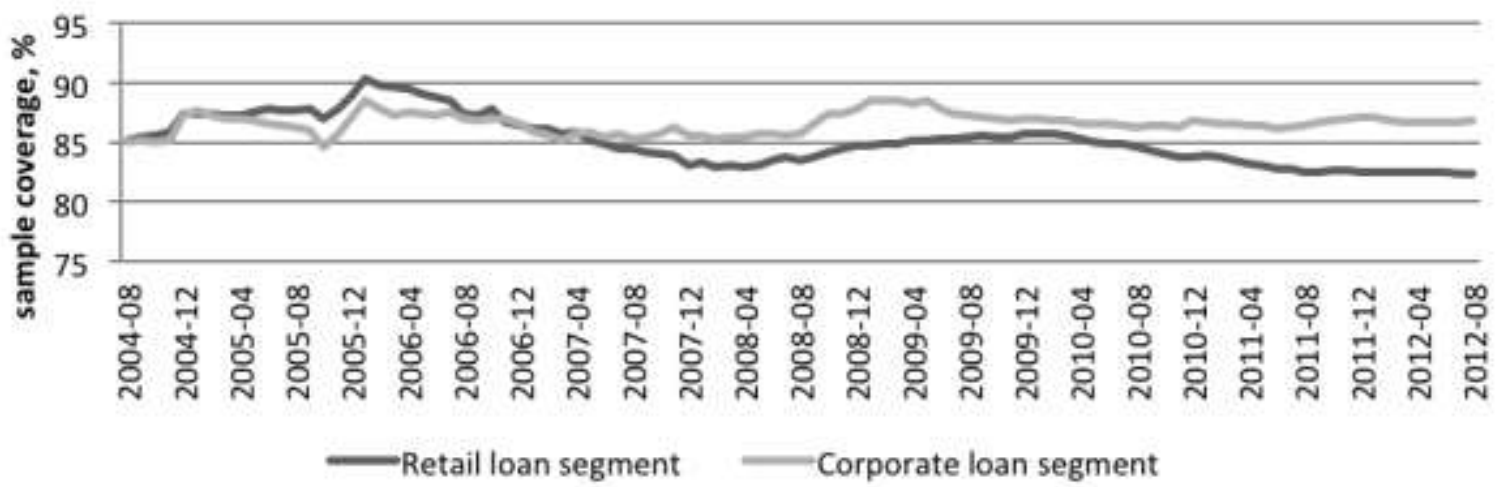

Figure 7: Sample coverage by segments

\subsection{Choice of variables for the models}

Aggregate bank-specific variables were calculated from Mobile database and monthly macroeconomic indicators were provided by CBR resources, Prime-TASS macroeconomic information agency and Joint Economic and Social Data Archive of Higher School of Economics.

From the existing literature discussed earlier in Section 2 we picked up a number of variables which were detected to correlated with NPL in different sectors. For the retail sector these are total GDP index, rouble/dollar real exchange rate, inflation measured by CPI, price of Brent oil, real disposable income, money aggregate M0 (all coins and notes in circulation), real interest rate, total volume of retail loans provided, average capital adequacy ratio across banking system, return on assets (ROA) and ROA instability (defined in Solntsev et al. (2010) as squared deviation of ROA from its average value for the period). For the corporate loan sector besides the mentioned variables excluding the total volume of retail loans provided we considered the index of industrial production, real investment in fixed assets and the total volume of corporate loans provided. Most of the variables show significant correlation measured in stock terms but clearly these series are not stationary and the correlation between them may root in general trend of the economy or other reasons, hence we take natural logarithm of growth in each variable. Regarding NPL in corporate sector log of GDP growth (Y), log of investment in fixed assets growth (INV), $\log$ of M0 growth (M0) and $\log$ of total corporate loans provided (CL) are significantly correlated with our variable of interest (NPL_C) and the correlations are reported in Table 1. The signs might seem puzzling: according to the reported values higher GDP growth and lower corporate credit loan growth are associated with the higher growth of NPL. This effect is likely to occur because of the lagged response of NPL on the considered variables and this issue will be dealt with further.

Table 2 reports variables significantly correlated with NPL in retail loan sector. They are the same as in the corporate model with the only difference that we consider retail loans (RL) here. Although correlation sign between total amount of loans provided with NPL in retail sector is positive it is puzzling why investment in fixed assets has rather high correlation with non-performing loans in retail sector while correlation with GDP is insignificant on $5 \%$ level.

Table 1: Correlation matrix for corporate loan model

\begin{tabular}{|llllll|}
\hline & NPL_C & Y & INV & M0 & CL \\
\hline NPL_C & 1.0000 & & & & \\
Y & $0.3116^{*}$ & 1.0000 & & & \\
INV & $0.2316^{*}$ & 0.0578 & 1.0000 & 1.0000 & 1.000 \\
M0 & $0.3827^{*}$ & $0.2123^{*}$ & $0.7313^{*}$ & -0.0360 & \\
CL & $-0.2817^{*}$ & 0.0778 & -0.0270 & & \\
\hline$*$ - 5\% significance level & & & & \\
Source: author's calculations & & & & \\
\hline
\end{tabular}


Table 2: Correlation matrix for retail loan model

\begin{tabular}{|llllll|}
\hline & NPL_R & Y & INV & M0 & RL \\
\hline NPL_R & 1.0000 & & & & \\
Y & 0.1553 & 1.0000 & & & \\
INV & $0.3428^{*}$ & $0.2123^{*}$ & 1.0000 & 1.0000 & \\
M0 & $0.4430^{*}$ & 0.0578 & $0.7313^{*}$ & $0.2513^{*}$ & 1.000 \\
RL & $0.3540^{*}$ & $0.2655^{*}$ & $0.3100^{*}$ & & \\
\hline$*$ - 5\% significance level & & & & \\
Source: author's calculations & & & & \\
\hline
\end{tabular}

Nevertheless, it is significant on $15 \%$ and for the model for two segments to be comparable, we include GDP growth in further analysis.

ADF test concludes that NPL_R, NPL_C, INV, M0, RL and CL are I (0) and Y is I (1) series, so we define dY as the first difference in log GDP growth and use it in further regressions.

\subsection{Model Specification}

Now we determine the optimum lag structure for the models. The decision on lag structure is closely connected with the issue of stability of VAR: we may include more lags in the model but it will not satisfy the stability condition ${ }^{2}$. After we tried various VAR lag specifications it was found that VAR is stable only if for lags smaller than or equal to 9 , hence we have to focus on short-run perspective because of relatively small sample (96 months in total). Hannan and Quinn (HQIC) and Schwarz-Bayesian (SBIC) determine the $2^{\text {nd }}$ lag to be optimal while the final prediction error (FPE) and Akaike's (AIC) criterion decide on the $9^{\text {th }}$ lag for both models hence we include lags from 1 to 9 in our specification. Wald test for lag structure suggests that all lags are jointly significant and should be employed in the model. The roots of the companion matrix lie inside the unit circle, hence stability condition is satisfied.

Hence, we firstly estimated the following reduced-form VAR model separately for retail loans and corporate loans:

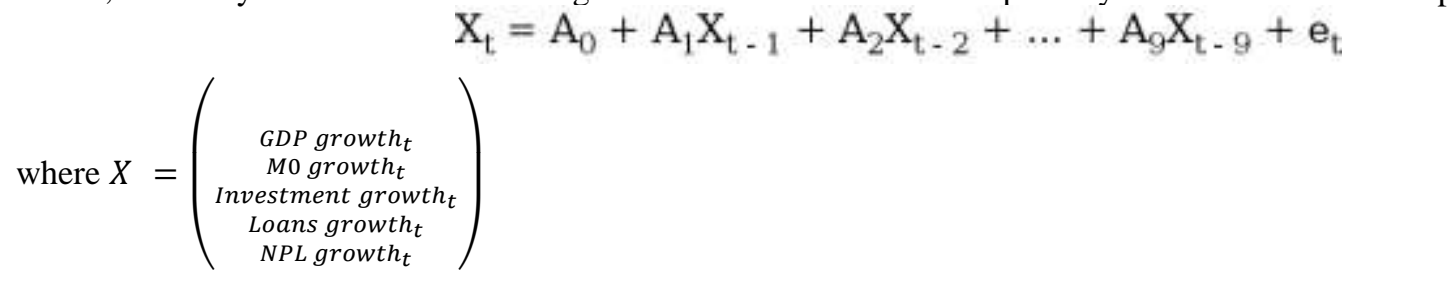

The goodness of fit of the reduced-form VAR models is presented in Table 3 below. As we can see $\mathrm{R}^{2,}$ values are rather high ( 0.77 on average for corporate loan model and 0.80 for retail loan model).

However, although reduced-form model fits the data reasonably well and can be used for forecasting it does not identify cause-effect relationships and its error terms are comprised of shocks in all other variables. Hence, now we proceed to structural form VAR to be able to estimate actual cause and effect relations and examine the impact of macro shocks on the ratio of non-performing loans.

Based on statistical inference (Granger causality tests) and basic economic intuition we propose the following ordering. It is reasonable to take M0 as an exogenous variable set by CBR, and its growth is likely to affect interest rates, which shapes investment growth (INV), while the latter is a determinant of GDP growth. These macroeconomic variables together will shape the amount of loans provided in both sectors and finally all the mentioned variables influence NPL growth. Thus, we estimate the structural model using the ordering we stated for Cholesky decomposition.

\footnotetext{
${ }^{2}$ Eigenvalue stability condition can be thought of as stationary condition from one-dimensional time series analysis applied to multivariate time series analysis. In order for it to be satisfied in one-dimensional time series analysis the roots of the characteristic equation must lie inside the unit circle, and for a VAR the roots of the companion matrix must lie inside the unit circle. This condition is needed in order to be able to invert AR process into infinite-order MA process; practically it is required to derive IRFs and intuitively it is needed to eliminate the possibility of explosive process in the system.
} 
Table 3: Goodness of fit of reduced-form VAR models

\begin{tabular}{|c|c|c|c|c|c|}
\hline \multicolumn{6}{|c|}{ Corporate loan segment } \\
\hline Equation & 1st dif GDP gr & M0 growth & $\begin{array}{l}\text { Investment } \\
\text { growth }\end{array}$ & Loans growth & NPL growth \\
\hline No. of parameters & 46 & 46 & 46 & 46 & 46 \\
\hline $\mathrm{R}^{2}$ & 0.91 & 0.75 & 0.87 & 0.65 & 0.69 \\
\hline$\chi^{2}$ & 866.92 & 262.48 & 585.54 & 160.31 & 189.06 \\
\hline $\mathrm{P}>\chi^{2}$ & 0.0000 & 0.0000 & 0.0000 & 0.0000 & 0.0000 \\
\hline \multicolumn{6}{|c|}{ Retail loan segment } \\
\hline Equation & GDP growth & M0 growth & $\begin{array}{l}\text { Investment } \\
\text { growth }\end{array}$ & Loans growth & NPL growth \\
\hline No. of parameters & 46 & 46 & 46 & 46 & 46 \\
\hline $\mathrm{R}^{2}$ & 0.90 & 0.77 & 0.86 & 0.82 & 0.68 \\
\hline$\chi^{2}$ & 761.44 & 292.94 & 533.16 & 402.12 & 183.21 \\
\hline $\mathrm{P}>\chi^{2}$ & 0.0000 & 0.0000 & 0.0000 & 0.0000 & 0.0000 \\
\hline
\end{tabular}

\section{Results}

\subsection{Results of stress testing: corporate loan segment}

We get the following estimation results for corporate loan model $(*-$ significant at $5 \%$ level, $* *$ - significant at $1 \%$ level):

$$
\left\{\begin{array}{l}
I N V=-7.81 M 0^{*}, \\
Y=0.04 M 0^{* *}-0.01 I N V^{*}, \\
C L=-0.07 M 0^{* *}+0.01 I N V+0.10 Y, \\
N P L_{C}=1.18 M 0-0.17 I N V+17.31 Y+14.02 C L^{* *} .
\end{array}\right.
$$

The main result for the corporate loan model is that only amount of corporate loans provided turns out to be significant determinant of the ratio of non-performing loans while macroeconomic factors are not, as can be seen from (10). This indicates that corporate loan segment is prone to macro shocks while $1 \%$ increase in growth of total amount of credit provided leads to $14.02 \%$ increase in NPL growth. The consequences of a one standard deviation shock in corporate loan growth on corporate NPL are depicted on Figure 8. Standard deviation of corporate loan growth for the considered period has been $2.5 \%$ and monthly growth for August 2012 was $2.3 \%$, hence we are considering a monthly doubling of growth rates of corporate loans. This leads to almost 8-percentage point's increase in NPL growth for the first month on impact, compensated by almost the same 8 percentage points drop in the second month after shock; for the next six months the effect fades and NPL growth returns to pre-shock level.This leads us to the conclusion that corporate loan segment is rather prone not only to macro shocks but to volume of loans shock as the effect of a shock appears to be very short termed ( 2 months) and has no serious consequences on quality of loans measured by NPL growth.

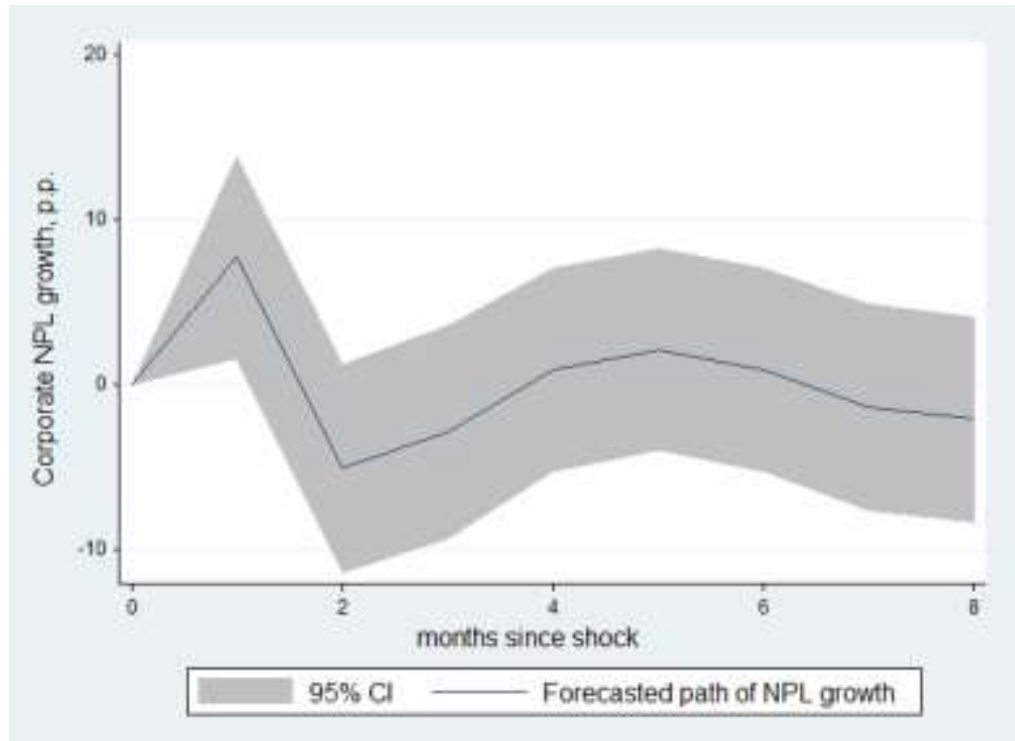

Figure 8: Impact of corporate loan growth shock 


\subsection{Results of stress testing: retail loan segment}

On the contrary, for the retail loan model macroeconomic variables are strongly significant while the growth in retail loans is not, hence retail loan segment is sensitive to macroeconomic environment while it is insensitive to volume of retail loans growth, as we see from (14).

As for the macroeconomic model, M0 growth is indeed a highly significant determinant of investment growth and $1 \%$ increase in M0 growth leads to $7.26 \%$ drop in investment growth, which is intuitively clear: inflation brings about uncertainty and higher interest, which slows down investment growth.

$$
\left\{\begin{array}{l}
I N V=-7.26 M 0^{*} \\
Y=0.01 M 0^{* *}-0.01 I N V^{*} \\
R L=-0.10 M 0^{*}+0.01 I N V-0.02 Y \\
N P L_{R}=-6.11 M 0^{* *}-0.45 I N V^{* *}-16.51 Y-1.17 R L
\end{array}\right.
$$

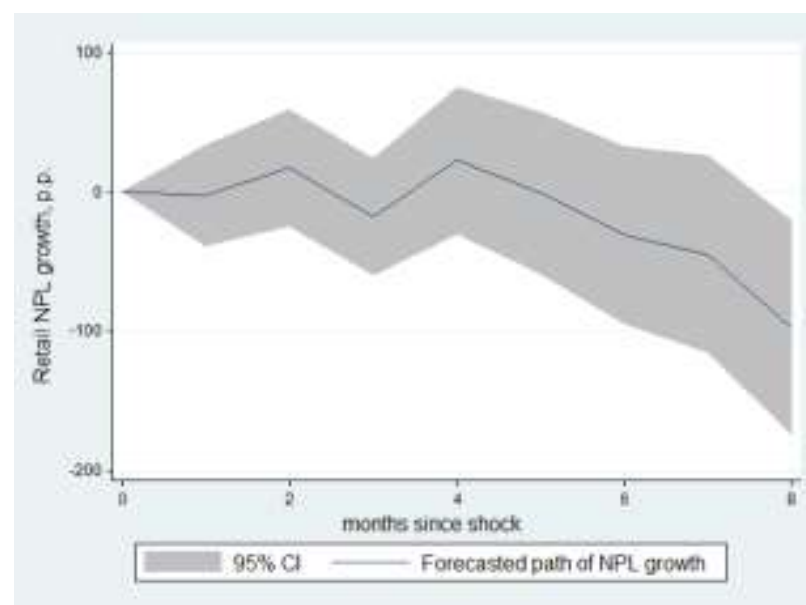

Figure 9: Impact of M0 growth shock

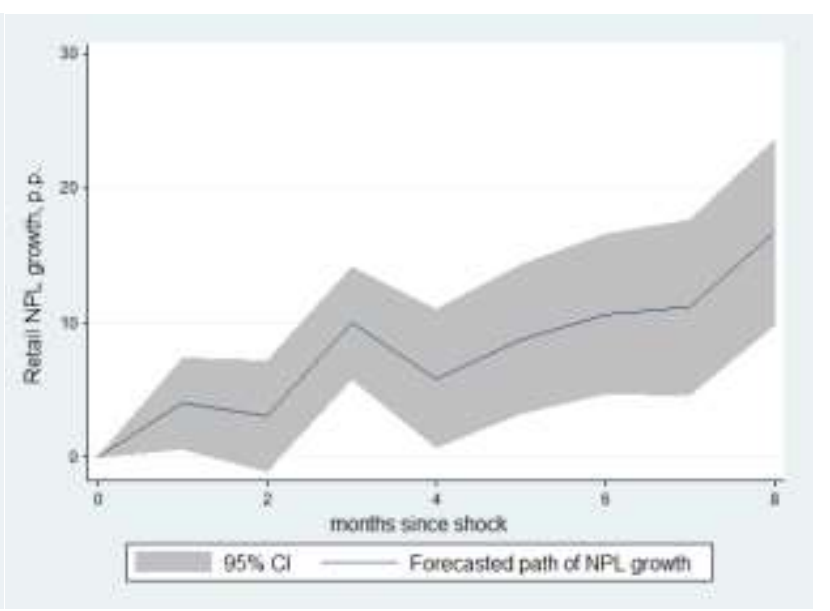

Figure 10: Impact of investment growth shock

The key point to note is that M0 and investment growth significantly influence the ratio of NPL in retail sector while GDP growth and volume of retail loans have an ultimately insignificant effect. Figures 9 and 10 reflect the impacts of one standard deviation shock in M0 and investment growth on NPL in retail respectively. Hence if monthly inflation increases by $0.5 \%$ this would increase NPL growth by around $15 \%$ on the second and the fourth months after the shock but as the estimation shows on Figure 9 after the $6^{\text {th }}$ month NPL starts to decrease rapidly and by the $8^{\text {th }}$ month any growth in NPL stops as it is forecasted to fall by $100 \%$. The possible explanation could be that at first increased inflation brings about higher uncertainty and on impact the proportion of affected customers which stop paying to the bank increases (in two waves - on the $2^{\text {nd }}$ and $4^{\text {th }}$ month), however several months after borrowers reap the benefits of inflation: the real value of interest payments decreases and, therefore, it becomes easier for the borrowers to repay the loan, hence NPL growth ceases.

As for the one standard deviation shock in investment growth, which is equivalent to triple increase compared to monthly rate as of August 2012, as reflected on Figure 10 it would lead to steady surge in NPL growth - around 5\% after a month, reaches $10 \%$ after three months and grows to exceed $15 \% 8$ months after the original shock. We note that the effect does not fade although it is rather small in absolute value compared to the impact of inflation shock.

\section{Conclusion}

This study develops a statistical approach to stress testing, firstly, conducting analysis on institutional level among systematically important state banks, and secondly, performing stress tests of retail and loan segments based on VAR model of interaction between financial and real economy sector.

Analysing major banks with state ownership as of the $1^{\text {st }}$ of September 2012 under the developed Credit Risk - Return Stability framework we find that the same banks tend to exhibit similar patterns in terms of risk-return strategies in corporate and retail segments, with Gazprombank showing exceptionally strong position prone to credit risk (especially in retail credit segment) and remaining on the median in terms of returns stability while Sberbank, although commonly acknowledged as rather safe remains on the median in terms of credit risk and below the median in terms of return stability, with significantly weaker position in the retail loan sector. Banks from VTB group were found to show alarmingly high exposure to credit risk especially in corporate loan segment while remaining close to the median in 
terms of return stability. Generally, corporate loan sector is found to be more risky on average than the retail. This analysis is valuable both for individual bank risk management and to the supervisory authorities as controlling of systematically important institutions is acknowledged to be more and more important especially in the light of the 2008-2009 global financial crisis.

Consequently, we estimate a VAR model, which links aggregated financial sector indicators such as growth in average NPL and growth in total amount of loans provided for each segment of credit market with macroeconomic variables: GDP growth, money aggregate M0 growth and growth in investment in fixed assets (monthly data, September $2004-$ September 2012). We find that NPL in corporate loans is significantly influenced only by the total amount of corporate loans provided; hence, it is prone to macroeconomic shocks. Opposite to that, growth for loans is not a significant cause of NPL in the retail sector, while growth in M0 and investment do have a significant impact on retail NPL ratio. This suggests that macroeconomic condition influence primarily the retail sector, which is three times less than corporate, hence only one-quarter of total loan market is vulnerable to macro shocks. A one standard deviation shock in M0 growth (which is equivalent to $0.5 \%$ increase in monthly inflation) increases NPL growth in retail loans by $15 \%$ during the first four months but then leads to rapid decline and cease of NPL growth by the $8^{\text {th }}$ month after shock. One standard deviation shock in the growth of investment in fixed assets leads to a steady increase in retail NPL growth, reaching $20 \%$ by the $8^{\text {th }}$ month after the initial disturbance.

The major conclusion is that macroeconomic shocks (namely, inflation and investment growth shocks) have considerable impact on credit risk in retail loan segment of Russian credit market, but do no significant impact on the corporate loan sector. On the contrary, the growth of loan market itself does not influence retail loan segment but has a significant impact on the corporate, though the effect of a shock fades after five months. Given that recently the growth rates of the retail segment have been almost twice as much as in the corporate supervisory authorities should strengthen macroeconomic policy control to prevent sharp rises in retail defaults. In case of a further surge in amount of corporate loans provided CBR should take preventive measures to avoid consequent rise in credit risk.

\section{References}

- BCBS, 2009. Principles for sound stress testing practices and supervision. Basel Committee on Banking Supervision, May, 2009.

- $\quad$ Blaschke, W, M T Jones, G Majnoni and S M Peria, 2001. Stress testing of financial systems: an overview of issues, methodologies, and FSAP experiences", International Monetary Fund Working Paper.

- Central Bank of Russia, 2012. Financial Stability Review for 2011. Research and Information Department.

- Čihák, M., 2007. Introduction to Applied Stress Testing; IMF Working Paper WP/07/59, International Monetary Fund, March 2007.

- Fungáčová Z. and Jakubík P., 2012. Bank stress tests as an information device for emerging markets: The case of Russia. BOFIT Discussion Papers 3/2012, 10.2.2012

- Ivičić L., Kunovac D. and Ljubaj I., 2008. Measuring Bank Insolvency Risk in CEE Countries

- The Fourteenth Dubrovnik Economic Conference Organized by the Croatian National Bank"

- IMF, 2011a. Russian Federation: Technical Note on Stress Testing of the Banking Sector. November 2011. IMF Country Report No. 11/334

- IMF, 2011b. Toward Operationalizing Macroprudential Policies: When to Act? Global Financial Stability Report, Chapter 3, September.

- IMF, 2012. Macrofinancial Stress Testing - Principles and Practices. Prepared by the Monetary and Capital Markets Department.

- $\quad$ Ong L.L., Maino R., Duma N., 2010. Into the Great Unknown: Stress Testing with Weak Data. IMF Working paper WP/10/282

- Pestova A., 2012. Predicting aggregate credit risk of the banking sector: dynamic panel data analysis. 32nd International Symposium on Forecasting Boston 24-27 June 2012

- $\quad$ Roy, A.D., 1952. Safety first and the holding of assets. Econometrica 20 (3), 431-449.

- Solntsev O., Mamonov M., Pestova A., 2012. Estimation of system effects from stricter prudential regulation of banking sector: stress test results. Questions of Economics. №8, p.4-31 [in Russian]

- Sorge M., 2004. Stress-testing financial system: an overview of current methodologies. BIS Working Papers No 165. 